\title{
A Hydraulic Experimental Study of a Movable Barrier on a Revetment to Block Wave Overtopping
}

\author{
Byeong Wook Lee, Jihye Seo, Woo-Sun Park and Deokhee Won * \\ Korea Institute of Ocean Science and Technology (KIOST), 385 Haeyang-ro, Yeongdo-gu, Busan 49111, Korea; \\ bwlee17@kiost.ac.kr (B.W.L.); jhseo@kiost.ac.kr (J.S.); wspark@kiost.ac.kr (W.-S.P.) \\ * Correspondence: thekeyone@kiost.ac.kr; Tel.: +82-51-664-3565
}

Received: 8 November 2019; Accepted: 19 December 2019; Published: 20 December 2019

\begin{abstract}
This paper presents a design for a movable barrier on the revetment of the Haeundae Marine City in Busan, the Korea. This movable barrier was developed to use as a tourist deck in a normal state and to block wave overtopping in an abnormal state. To carry out the physical experiment in a wave flume, the model structure was reduced to a scale of $1 / 36$ compared to the field structure. The discharge of the wave overtopping, the uplift pressure acting on the under surface of a non-standing barrier, and the wave pressure acting in front of a standing barrier were measured to analyze the hydraulic characteristics of the movable barrier. The results show that the impulsive pressure acts on the movable barrier, although the overtopping discharge is less than the allowable limit. When designing a movable barrier at a full scale, engineers should consider the impulsive pressure to secure the barrier's stability on the target site.
\end{abstract}

Keywords: movable barrier; wave overtopping; wave pressure; storm surge; hydraulic experiment

\section{Introduction}

The ports connecting marine and land transportation are expanding to perform various functions, such as waterfront space and eco-friendly facilities, as well as fundamental functions for commerce and the fishery. These ports also include functions to create safer coasts and ports through the reinforcement of existing facilities, in addition to the development of port peripheral areas linked with leisure facilities. Thus, it is necessary to comprehensively review the planning aspects of the development and use of port peripheral areas in harbor structures. Accordingly, the mutual influence of facilities in the hinterland is complicated by the topographical characteristics and economic and social functions of ports. However, in accordance with the trend of placing more emphasis on the quality of life, sensitivity to disasters caused by climate change has increased. Hence, the needs for harbor structures to reduce disasters has increased. In particular, in areas where serious disasters are expected, the interest for disaster-reducing facilities is high.

As global warming due to climate change is expected to increase the intensity and frequency of typhoons [1], storm surges must be urgently prevented because of an increase in the expected casualties and flood damage. As typhoon intensity is expected to increase because of the rising sea levels and temperatures due to the effects of global warming [2], the damage caused by storm surges is expected to increase rapidly. Hence, the requirement to reinforce coastal structures has increased with increases in wave height. Coastal and water side areas should be especially protected from inundation by wave overtopping. To quantify wave overtopping in coastal areas, the EurOtop manual provides empirical formulas for various coastal structures through physical experiments [3], and a numerical model was developed to apply simple harbor geometry [4]. Various types of barriers have been constructed to prevent such inundation. The Eider Barrier of the radial gate type was built in 1973, in Germany [5]. This barrier is part of the dike defense line of the North Friesian coast. In England, the Thames Barrier 
was built in 1982 to prevent inundation by high tides (with floods from the upstream of the Thames) and had its official opening in 1984 [6]. Gates of the rotary segment type are normally located on a flat face flush with the river bed when in the gate housing and then rotated 90 degree to close the barrier in an emergency. In 1953, the south-western area of the Netherlands was threatened by a severe storm and was flooded by sea water. After this disaster, the storm surge barrier called the Maeslant Barrier was built in 1997, in the Netherlands [7]. This barrier consists of two sector-gates. The same type of barrier, called the St. Petersburg Flood Protection Barrier, was built in 2011 in Russia [8]. In a normal state, these gates are parked in docks. However, these gates are moved to the center of the waterway to close the channel during severe storms. In 2013, the Venice Flood Barrier, which is one the first four gates of the MOSE project, was built at the Lido inlet in Italy [9]. These gates of the flap type are raised by compressed air pumped into each hollow gate.

Recently, a movable barrier type was proposed, such as a flap type that could be installed on the revetment, as shown in Figure 1 [10]. This barrier is usually used as a tourist deck but stands up to prevent wave overtopping when a storm surge occurs. Movable barriers should have an effective operational method and the ability to adequately block against wave overtopping. A movable barrier is composed of a double deck, with two hinges installed on the upper deck. Hinges are installed at the end of the deck and the middle of the deck. When the upper deck on the land side is pushed by the actuators, the barrier stands in the form of a triangle since rotation occurs at the hinge. To resist upward forces, such as the uplift force, three-axis bearings are installed on the lower deck. The height of the movable barrier can be adjusted to prevent inundation by wave overtopping via the designed conditions at the target site. However, impulsive pressure can occasionally occur at a barrier such as a vertical wall, even though the barrier properly blocks wave overtopping. Thus, it is important to carry out physical experiments to accurately determine the designed wave force [11].

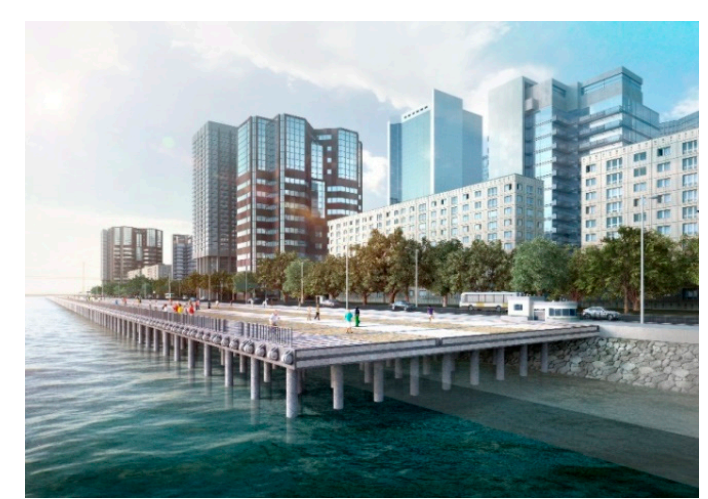

(a)

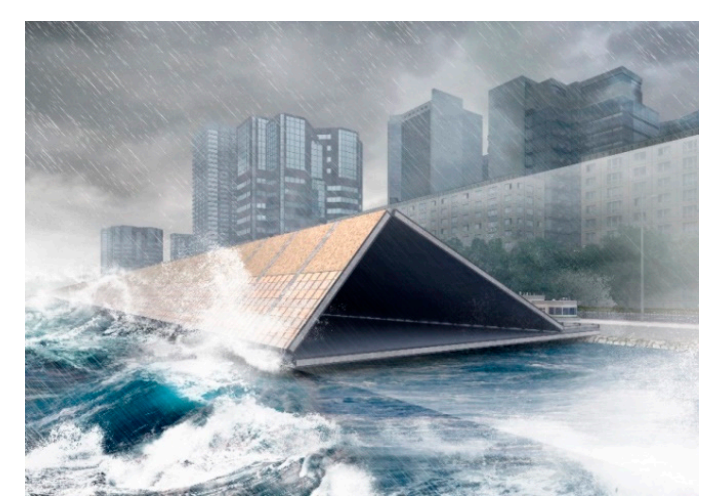

(b)

Figure 1. Sketch of the developed movable barrier; (a) in a normal state; (b) in an abnormal state.

In this study, a movable barrier is considered on the revetment of Haeundae Marine City in Busan, Republic of Korea. The design of the movable barrier is carried out for the target site, unlike the developed movable barrier [10]. However, the operation method and the purpose are the same as those of the developed movable barrier, as shown in Figure 1. A physical experiment was conducted to quantitatively analyze the discharge of wave overtopping in a wave flume, and the wave pressures acting on the movable barrier are later measured to determine the occurrences of impulsive wave pressure to reflect the working design stage. The model structure was designed simply to measure data for a standing barrier and a non-standing barrier. In Section 2, the experimental setup and test conditions of this study are summarized. In Section 3, the results are presented for the wave overtopping and wave pressure of the physical experiment. Finally, the conclusion is given in Section 4 . 


\section{Physical Experiment}

\subsection{Experimental Setup}

The experiment was conducted in a wave flume located at the Korea Institute of Ocean Science and Technology (KIOST) in Busan, Republic of Korea. The dimensions of the wave flume are $50 \mathrm{~m}$ in length, $1.2 \mathrm{~m}$ in width, and $1.6 \mathrm{~m}$ in depth [12]. The wave flume is equipped with a piston-type wave maker developed by VTI (Vazquezy Torres Ingenieria, Spain) Corporation. The wave maker can generate a regular wave, an irregular wave, and a solitary wave. The wave paddle is made of stainless steel and glass fiber reinforced plastic. To reduce re-reflected waves at the wave paddle, an active absorption system was applied to the wave generation software (AwaSys 7), based on the digital filtering of signals from the wave gauges in the nearfield [13,14]. Passive wave absorbers were placed to absorb wave energy at both ends of the wave flume. As shown in Figure 2a, 11 wave gauges (Equations (1)-(11)) were placed, and the model structure made of acrylic plates was placed $32.13 \mathrm{~m}$ from the left end of the wave flume. Without the model structure, the wave gauges from Equations (9) to (11) are used to analyze the incident wave heights of the target waves. The distance between Equations (9) and (10) is $0.3 \mathrm{~m}$, and the distance between Equations (10) and (11) is $0.5 \mathrm{~m}$.

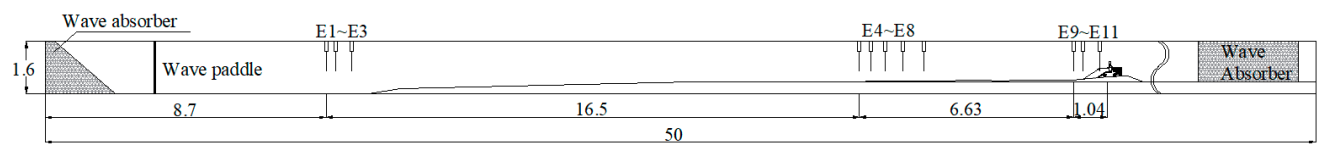

(a)

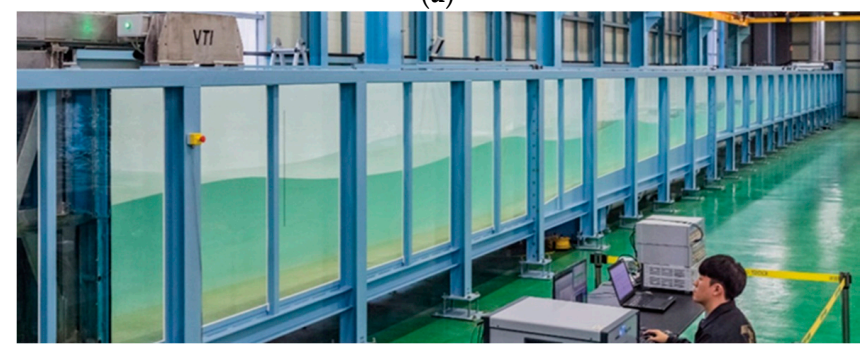

(b)

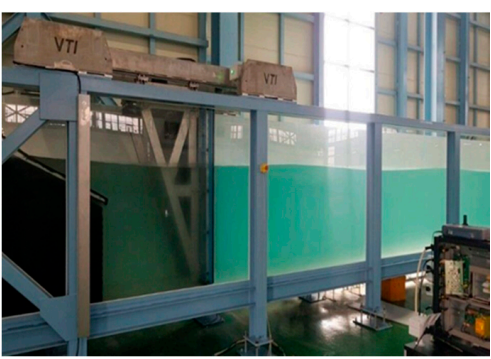

(c)

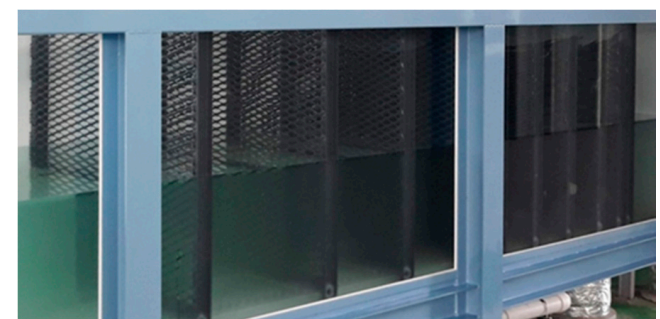

(d)

Figure 2. Schematic sketch of the wave flume with the location of the model structure, with the wave gauges and pictures of the experimental equipment; (a) side view (unit: m); (b) wave flume; (c) wave maker; (d) passive absorbers.

Figure 3 shows a conceptual design for the movable barrier on the revetment of Haeundae Marine City in Busan, Republic of Korea. The height of the movable barrier was designed to be $6.5 \mathrm{~m}$. In a normal state, during which the movable barrier does not stand, the designed sea level is the approximate highest high water (Approx. H.H.W.). Under an abnormal state activating the movable barrier, the designed sea level is considered to be the storm surge height and the sea level rise (SLR). In this study, a 1/36 scale model was adopted to consider the bathymetry in the wave flume. The similitude ratio for the Froude similarity was then scaled down. At this scale, the weight of the tetrapod (T.T.P) was $3.051 \mathrm{~N}$ per each. T.T.Ps were randomly placed (considering those placed on the target site) for all experiments. 


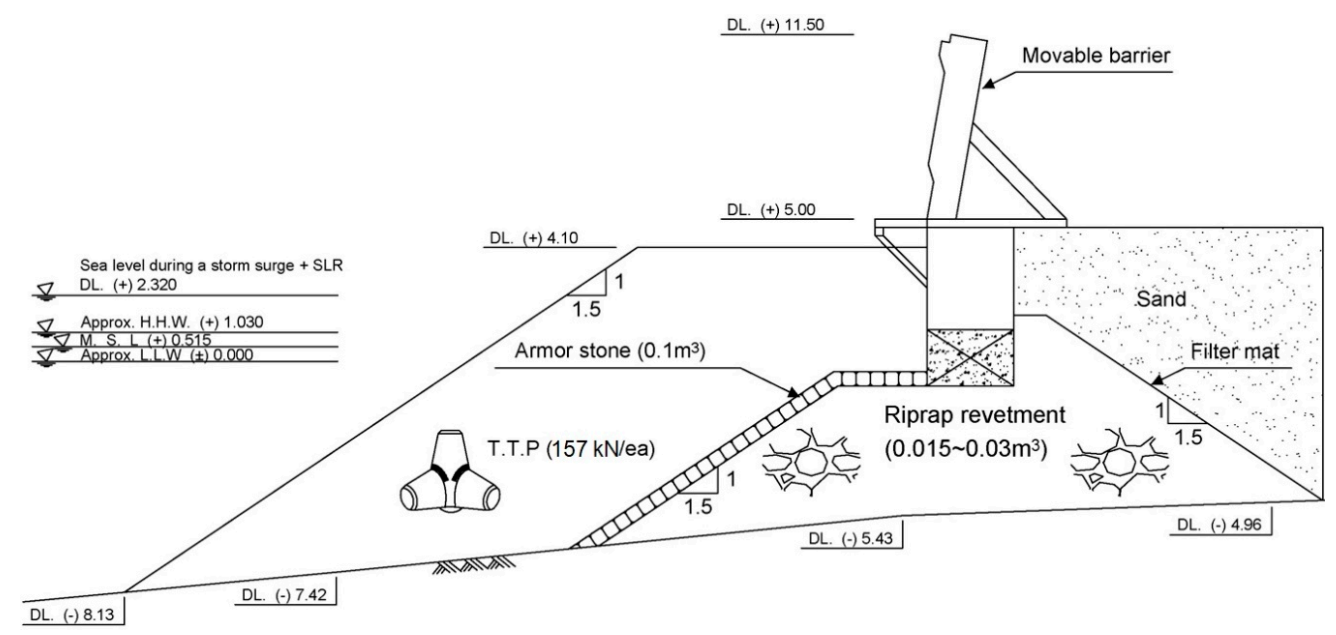

Figure 3. Conceptual design of the movable barrier on the target site (unit: $\mathrm{m}$ ).

The first purpose of the experiments was to measure the discharge of the wave overtopping. Thus, a waterway was placed on top of the movable barrier, as shown in Figure 4. A water trap was installed behind the model to capture the overtopped waters during the experiment. In the water trap, a flowmeter (Manufacturer: NTON INTERNATIONAL, China; Model: K24 turbine digital oil fuel flow meter gauge for chemicals liquid water) was installed to detect the discharge of the wave overtopping. The measurement range was 0.01 to $0.12 \mathrm{~m}^{3} / \mathrm{min}$, and the measurement accuracy was less than $1 \%$. The discharge was measured and calculated during the full test time to be $30 \mathrm{~min}$, corresponding to a full-scale time of $3 \mathrm{~h}$. Figure 4 also shows the installed model structure in the wave flume. The model structure has been reproduced as similar as possible the design of the target site. The second purpose of this experiment was to measure the wave pressure and to determine the occurrences of impulsive wave pressures acting on the movable barrier, as shown in Figure 5. In order to characterize the wave pressure acting on the movable barrier, pressure measurements were taken at four points $\left(\mathrm{p}_{1}\right.$ to $\left.\mathrm{p}_{4}\right)$ in a normal state and at eight points $\left(\mathrm{p}_{1}\right.$ to $\left.\mathrm{p}_{8}\right)$ in an abnormal state. The pressure gauges use disk-type pressure transducers with $10 \mathrm{~mm}$ diameters. Table 1 shows the specification of the disk-type pressure transducer [15]. All pressure gauges were mounted at the digging holes in the desired locations of the model structure. To protect the pressure gauges from the impact of the armor unit, a safe guard was installed in front of the mounted pressure gauges. This safe guard is made of a thin perforated plate, which has large perforations to minimize the influence of the measured pressures. In Figure $5 \mathrm{a}$, the locations of the 4 points, $p_{1}$ to $p_{4}$, from $0 \mathrm{~m}$ of the datum level (DL) are 1.03, 2.32, 3.61, and $4.70 \mathrm{~m}$, respectively. Here, $\mathrm{p}_{4}$ was placed to measure the uplift pressure acting on the movable barrier in a normal state. In Figure $5 b$, the locations of the 8 points, $p_{1}$ to $p_{8}$, from $0 \mathrm{~m}$ of the datum level are 1.03, $2.32,3.61,4.70,5.67,6.62,7.89,9.20$, and $10.46 \mathrm{~m}$, respectively. Here, we placed $\mathrm{p}_{4}$ to $\mathrm{p}_{8}$ to measure the wave pressure acting on the movable barrier surface facing the outer sea in an abnormal state.

Table 1. Technical specification of the disk-type pressure transducer.

\begin{tabular}{cc} 
Manufacturer & SSK Company, Japan \\
Podel & Stainless steel \\
Material & \\
Rated capacity & $49.05 \mathrm{kPa}$ \\
Natural oscillation frequency & $7.8 \mathrm{kHz}$ \\
\hline
\end{tabular}




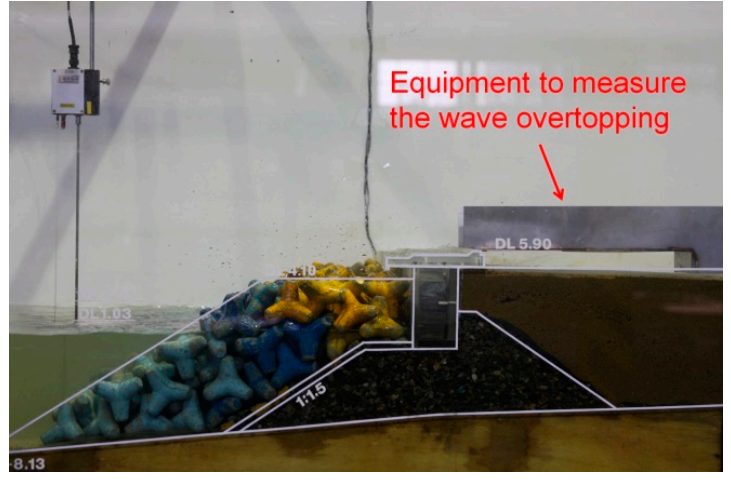

(a)

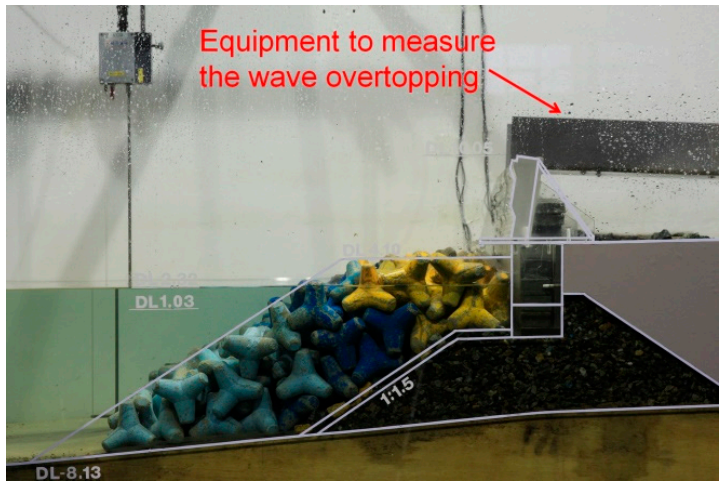

(b)

Figure 4. Photographs of the model structure; (a) non-standing barrier in a normal state; (b) standing barrier in an abnormal state.

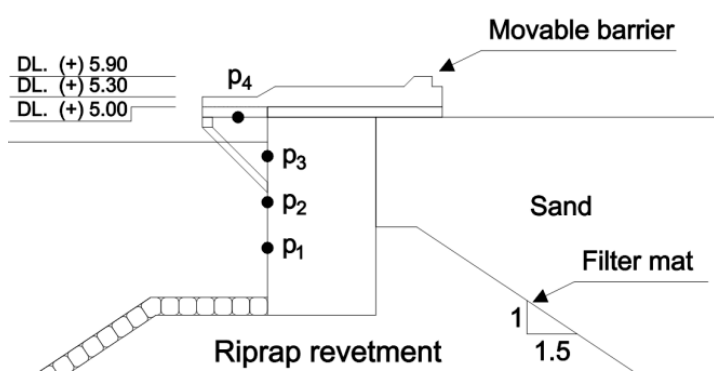

(a)

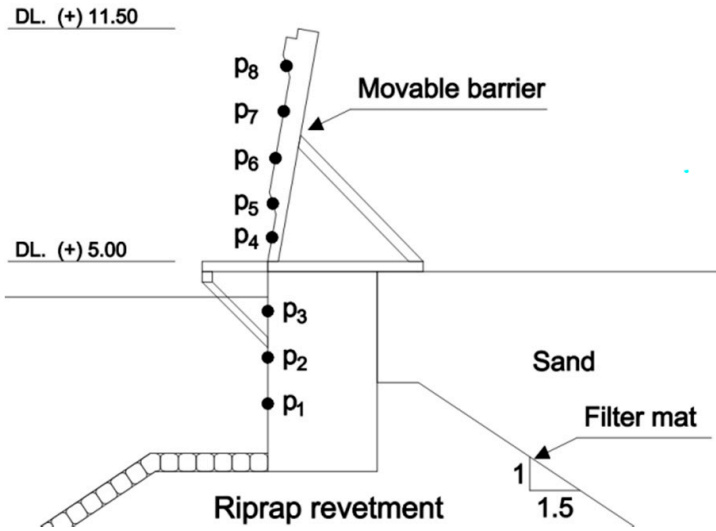

(b)

Figure 5. Location of the installed wave pressure gauges; (a) non-standing barrier in a normal state; (b) standing barrier in an abnormal state.

\subsection{Wave Conditions}

The physical experiment was conducted for irregular waves based on the JONSWAP spectrum [16] in the wave flume. The JONSWAP spectrum is defined as:

$$
S(f)=\beta_{J} H_{1 / 3}^{2} T_{p}^{-4} f^{-5} \exp \left[-1.25\left(T_{p} f\right)^{-4}\right] \gamma^{\exp \left[-\left(T_{p} f-1\right)^{2} / 2 \sigma^{2}\right]}
$$

where

$$
\begin{gathered}
\beta_{J}=\frac{0.0624}{0.230+0.0336 \gamma-0.185(1.9+\gamma)^{-1}}[1.094-0.01915 \ln \gamma] \\
T_{p} \cong T_{1 / 3} /\left[1-0.132(\gamma+0.2)^{-0.559}\right] \\
\sigma=\left\{\begin{array}{l}
\sigma_{a}: f \leq f_{p} \\
\sigma_{b}: f>f_{p}
\end{array}\right. \\
\gamma=1 \sim 7, \quad \sigma_{a} \cong 0.07, \quad \sigma_{b} \cong 0.09
\end{gathered}
$$

where the peak enhancement factor $\gamma$ controls the sharpness of the spectral peak, and 3.3 is the mean value. $H_{1 / 3}$ is the significant wave height, $T_{1 / 3}$ is the significant wave period, $T_{p}$ is the wave period corresponding to the frequency $\mathrm{f}_{\mathrm{p}}$ at the spectral peak, and $\sigma$ is the narrowness of the peak parameter. A method for separating the incident and reflected waves was used to estimate the test waves using three wave gauges (Equations (9)-(11)), as shown in Figure 2 [17]. The wave generation time is set to $30 \mathrm{~min}$ (assuming that the typhoon duration is $3 \mathrm{~h}$ for a full-scale time) for each test case. The number 
of component waves is about 630 to 830 , depending on the wave period. For example, when the wave period is $2.18 \mathrm{~s}$ in Table 2, the number of component waves is about 826, which is 30 min divided by $2.18 \mathrm{~s}$. When test waves are estimated without the model structure, the sampling frequency is $50 \mathrm{~Hz}$. In the test with the model structure, the sampling frequency is set to $600 \mathrm{~Hz}$ to measure the wave pressure acting on the movable barrier. If the impulsive wave pressure occurs in the test, $600 \mathrm{~Hz}$ is too low to measure the quantitative impulsive pressures. However, the sampling frequency is $600 \mathrm{~Hz}$ because the purpose of this experiment is to confirm the occurrence of impulsive pressures. As presented in Section 2.1, two different designed sea levels were selected based on the data of the Korea Hydrographic and Oceanographic Administration and some other reports [18-20]. On the target site, the significant wave heights and periods for the "10- and 50-year return period" were $4.35 \mathrm{~m} / 13.10$ $\mathrm{s}$ and $4.58 \mathrm{~m} / 17.22 \mathrm{~s}$, respectively [21]. The target site, which is geographically a cape, was opened to the seaside, and the sea bottom slope was too steep, at about $1 / 10$. Therefore, the incident wave close to the breaking limit propagated to the target site with a large amount of energy. Hence, the target wave was difficult to generate in the laboratory experiment. To solve this problem, the sea bottom of the real site was reproduced up to $12.2 \mathrm{~m}$ ( $440 \mathrm{~m}$ for the full-scale distance) toward the wave paddle from the model structure in the wave flume. At the model scale, the significant wave height $\mathrm{H}_{\mathrm{s}}$ and significant wave period $\mathrm{T}_{\mathrm{s}}$ were expressed as the target wave in the Table 2.

Table 2. Wave conditions.

\begin{tabular}{cccccccc}
\hline \multirow{2}{*}{ No. } & \multirow{2}{*}{ Designed Sea Level } & \multirow{2}{*}{ Return Period (year) } & \multicolumn{2}{c}{ Target Wave } & \multicolumn{3}{c}{ Estimated Test Wave } \\
\cline { 4 - 7 } & & $\mathbf{H}_{\mathbf{s}} \mathbf{( c m )}$ & $\mathbf{T}_{\mathbf{s}}(\mathbf{s})$ & $\mathbf{H}_{\mathbf{s}} \mathbf{( c m )}$ & $\mathbf{T}_{\mathbf{s}}(\mathbf{s})$ & $\mathbf{H}_{\mathbf{r}}(\mathbf{c m})$ \\
\hline 1 & Approx. H.H.W. & 10 & 12.08 & 2.18 & 12.00 & 2.17 & 3.29 \\
2 & Approx. H.H.W. & 50 & 12.72 & 2.87 & 12.80 & 3.00 & 3.92 \\
3 & Sea level during storm surge + SLR & 10 & 12.08 & 2.18 & 12.10 & 2.23 & 3.05 \\
4 & Sea level during storm surge + SLR & 50 & 12.72 & 2.87 & 12.80 & 3.00 & 3.36 \\
\hline
\end{tabular}

Test waves were generated several times to find values close to the target wave. Figure 6 shows two cases of the spectrum of test waves, since the other two cases had similar results. The solid line is the analytical solution, and the histogram shows the results of the experiment applying the method for separating the incident and reflected waves [17]. The peak enhancement factor $\gamma$ is 3.3 , and $T_{p}$ is the wave period corresponding to the frequency $f_{p}$ at the spectral peak. The results of the experiment have a similar tendency with those of the analytical solution. For all cases, the maximum relative error of the significant wave height is about $0.66 \%$, and the maximum relative error of the significant wave period is about $4.53 \%$. In Figure 6, the green bar is the incident wave, and the blue bar is the reflected wave. The coefficient of wave reflection $K_{R}$ is in the range of 0.25 to 0.31 . In the Harbor and fishery design criteria [22], the coefficient of the wave reflection for the natural beach is suggested to be in the range of 0.05 to 0.2 . Thus, the results of the experiment are slightly higher than those of the natural beach. This implies that wave absorbers in the wave flume correctly absorb the wave energy. Table 2 shows a detailed test of the wave conditions. 

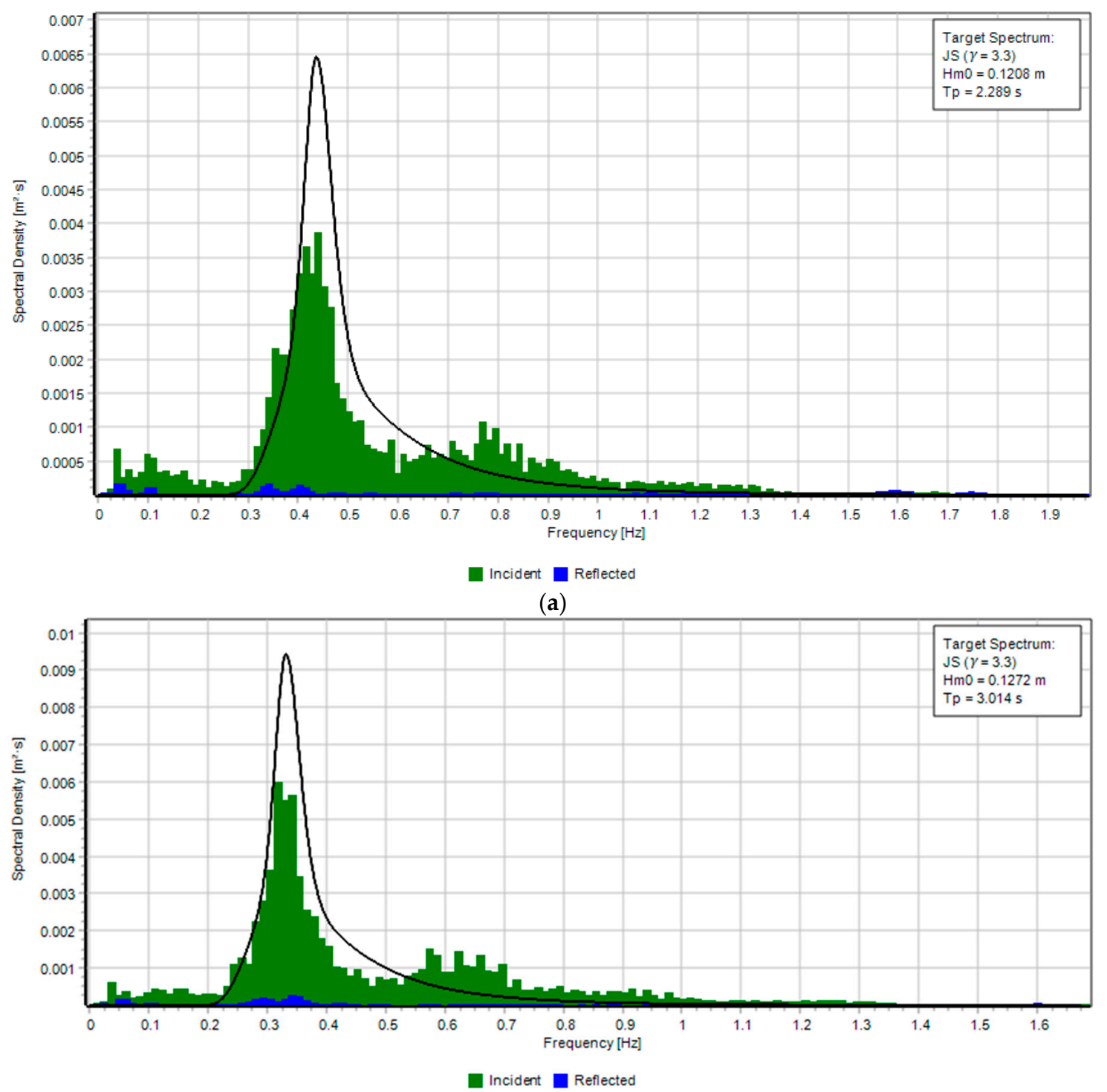

(b)

Figure 6. Spectrum of the test waves measured at E9 to E11 in Figure 2a; (a) approx. highest high water (H.H.W.) and a 10-year return period; (b) sea level during a storm surge with sea level rise (SLR) and a 50-year return period.

\section{Results and Discussion of the Physical Experiment}

\subsection{Wave Overtopping}

The target area is densely populated with skyscrapers just $20 \mathrm{~m}$ from the shoreline. In addition, this area is a place that many tourists visit. For this reason, it is necessary to not only secure the right view at normal times but also to prevent wave overtopping caused by storm surges. In order to cope with wave overtopping, a movable barrier was designed for the target site. As shown in Figure 5 and Table 2, experiments were conducted for eight cases by changing the water depths and the test waves with standing or non-standing barriers.

Figure 7 shows photographs taken when the water surface elevation was at its maximum, and Table 3 shows the results of the measured overtopping discharge. Figure 7a shows that a large amount of water is overtopped, even though the return period is 10 years. The allowable overtopping discharge is $0.01 \mathrm{~m}^{3} /(\mathrm{m} \mathrm{s})$ for areas crowded by private houses and public facilities in the hinterland, where serious disasters are expected because of the inflow of overtopped water and sprays [22]. 
The overtopping discharge at a full scale is $0.03 \mathrm{~m}^{3} /(\mathrm{m} \mathrm{s})$, as shown in Table 2. The result of this case is greater than the allowable limit, despite the minimum value among the test cases for the non-standing barrier. Thus, for this case, the movable barrier must stand to prevent wave overtopping. As shown in Figure 7b, two bullnoses on the movable barrier were designed to efficiently reflect the incident waves to the seaside. Although stairs perform this role well, the overtopped water can still be seen because of the large incident wave condition. However, the overtopping discharge at a full scale is $0.0099 \mathrm{~m}^{3} /(\mathrm{m} \mathrm{s})$, which is less than the allowable limit. The developed movable barrier properly prevents wave overtopping for the designed wave with a 50-year return period.

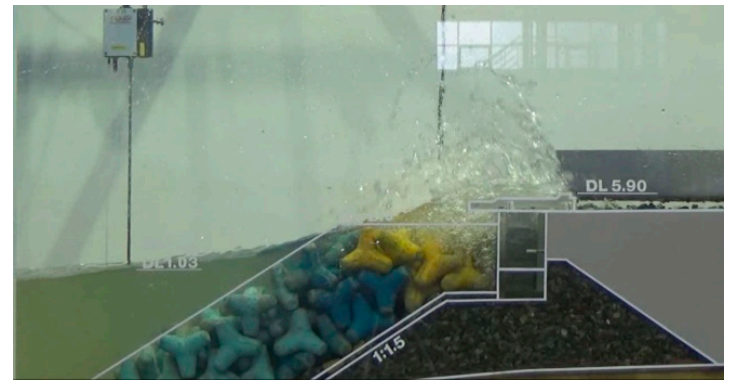

(a)

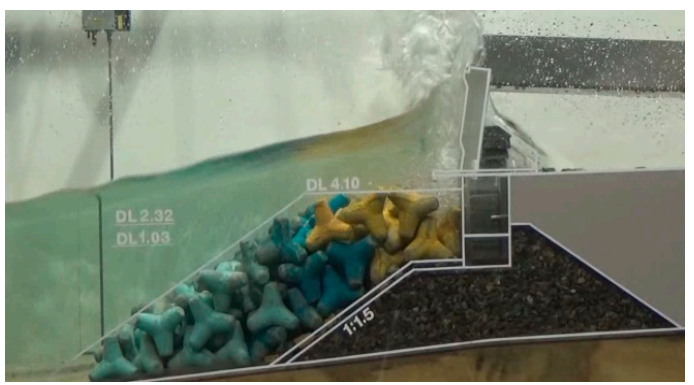

(b)

Figure 7. Photographs of the overtopping water for the maximum water surface elevation; (a) non-standing barrier for the 10-year return period and the approx. H.H.W. (No. 1, Table 2); (b) standing barrier for the 50-year return period and the sea level during the storm surge with the SLR (No. 4, Table 2).

Table 3. Results of the measured overtopping discharge.

\begin{tabular}{|c|c|c|c|c|}
\hline \multirow{2}{*}{$\begin{array}{c}\text { State of } \\
\text { Movable Barrier }\end{array}$} & \multirow{2}{*}{$\begin{array}{l}\text { Designed Sea } \\
\text { Level }\end{array}$} & \multirow{2}{*}{$\begin{array}{c}\text { Return Period } \\
\text { (year) }\end{array}$} & \multicolumn{2}{|c|}{ Overtopping Discharge $\left(\mathrm{q}, \mathrm{m}^{3} /(\mathrm{m} \mathrm{s})\right.$} \\
\hline & & & Model Scale & Full Scale \\
\hline \multirow{4}{*}{ Non-standing } & Approx. H.H.W. & 10 & $1.366 \times 10^{-4}$ & 0.0295 \\
\hline & Approx. H.H.W. & 50 & $5.043 \times 10^{-4}$ & 0.1089 \\
\hline & $\begin{array}{l}\text { Sea level during } \\
\text { storm surge }+ \text { SLR }\end{array}$ & 10 & $5.572 \times 10^{-4}$ & 0.1204 \\
\hline & $\begin{array}{l}\text { Sea level during } \\
\text { storm surge + SLR }\end{array}$ & 50 & $1.598 \times 10^{-3}$ & 0.3453 \\
\hline \multirow{4}{*}{ Standing } & Approx. H.H.W. & 10 & 0 & 0 \\
\hline & Approx. H.H.W. & 50 & $1.749 \times 10^{-5}$ & 0.0038 \\
\hline & $\begin{array}{l}\text { Sea level during } \\
\text { storm surge }+ \text { SLR }\end{array}$ & 10 & $1.106 \times 10^{-5}$ & 0.0024 \\
\hline & $\begin{array}{l}\text { Sea level during } \\
\text { storm surge + SLR }\end{array}$ & 50 & $4.602 \times 10^{-5}$ & 0.0099 \\
\hline
\end{tabular}

The wave energy for the 50-year return period is higher than that for the 10-year return period. As shown Table 3 , for the approx. H.H.W., the relative overtopping discharges (i.e., $\mathrm{q}_{\text {standing }} / \mathrm{q}_{\text {non-standing }}$ ) for the 10-year return period and the 50-year return period are zero and 0.0349 , respectively. This implies that the overtopping discharge increases when the wave energy increases. This result is also the same for the sea level during the storm surge with the SLR. All overtopping discharges are less than the allowable limit for the standing barrier. In order to cope with wave overtopping more efficiently, it is necessary to properly design energy dissipators on the movable barrier, such as wave return walls [23] or stepped revetments [24], to reduce the height of the barrier. Reducing the height of the barrier would be excellent in terms of utilizing the surrounding space and view.

The overtopping discharge of the movable barrier is now compared with the prediction equation for the overtopping discharge of the composite vertical wall proposed by EurOtop [3]. The composite vertical wall is the most similar comparison target in the EurOtop manual, even though T.T.Ps are 
not placed in front of the vertical wall. When the mound influence is significant (i.e., $d<0.6 \mathrm{~h}$ ), the prediction equations are suggested to be

$$
\begin{gathered}
\frac{q}{\sqrt{g H_{m 0}^{3}}}=1.3\left(\frac{d}{h}\right)^{0.5} 0.0014\left(\frac{H_{m 0}}{h \cdot s_{m-1,0}}\right)^{0.5}\left(\frac{R_{c}}{H_{m 0}}\right)^{-3} \text { Valid for } R_{c} / H_{m 0} \geq 1.35 \\
\frac{q}{\sqrt{g H_{m 0}^{3}}}=1.3\left(\frac{d}{h}\right)^{0.5} 0.011\left(\frac{H_{m 0}}{h \cdot s_{m-1,0}}\right)^{0.5} \exp \left(-2.2 \frac{R_{c}}{H_{m 0}}\right) \text { Valid for } R_{c} / H_{m 0}<1.35
\end{gathered}
$$

where $q$ is the overtopping discharge per meter of the structure's width, $g$ is the acceleration of gravity, $H_{m 0}$ is the significant wave height from the spectral analysis, $d$ is the water depth above the toe mound or the berm in front of the vertical wall, $h$ is the water depth in front of the toe of the structure, $R_{c}$ is the crest freeboard of the structure, and $s_{m-1,0}$ is the wave steepness with $L_{m-1,0}$. The wave steepness is given by

$$
s_{m-1,0}=\frac{H_{m 0}}{L_{m-1,0}}=\frac{2 \pi H_{m 0}}{g T_{m-1,0}^{2}}
$$

where $L_{m-1,0}$ is the spectral wave length in deep water, and $T_{m-1,0}$ is the spectral wave period. Equations (6) and (7) can predict overtopping discharge under conditions where impulsive overtopping is expected. An occurrence of impulsive overtopping is determined as

$$
\frac{d}{H_{m 0}} \cdot \frac{h}{L_{m-1,0}} \leq 0.65
$$

Figure 8 shows the definitions of the parameters related to Equations (6) and (7). The parameters for the movable barrier are defined similar to EurOtop's definitions, even though armor units (i.e., T.T.Ps) are placed in front of the vertical wall and the revetment. Table 4 shows detailed parameters at the model scale. The case where the overtopping discharge is zero in Table 3 is excluded. As shown in Table 4, for all cases, the mound has a significant influence (i.e., $d<0.6 \mathrm{~h}$ ), and the impulsive

\begin{tabular}{|c|c|c|c|c|c|c|c|c|c|c|}
\hline $\begin{array}{c}\text { State of } \\
\text { Movable Barrier }\end{array}$ & Designed Sea Level & $\begin{array}{l}\text { Return Period } \\
\text { (year) }\end{array}$ & $\begin{array}{c}H_{m 0} \\
(\mathrm{~m})\end{array}$ & $\begin{array}{c}T_{m-1,0} \\
(\mathrm{sec})\end{array}$ & $d(\mathrm{~m})$ & $h(\mathrm{~m})$ & $R_{c} / H_{m 0}$ & $\begin{array}{l}L_{m-1,0} \\
(\mathrm{~m})\end{array}$ & $S_{m-1,0}$ & $\frac{d}{H_{m 0}} \cdot \frac{h}{L_{m-1,0}}$ \\
\hline \multirow{4}{*}{ Non-standing } & Approx. H.H.W. & 10 & 0.120 & 2.17 & 0.0388 & 0.254 & 1.127 & 7.352 & 0.0163 & 0.0112 \\
\hline & Approx. H.H.W. & 50 & 0.128 & 3.00 & 0.0388 & 0.254 & 1.106 & 14.052 & 0.0091 & 0.0055 \\
\hline & $\begin{array}{l}\text { Sea level during storm } \\
\text { surge + SLR }\end{array}$ & 10 & 0.121 & 2.23 & 0.0746 & 0.290 & 0.822 & 7.764 & 0.0155 & 0.0230 \\
\hline & $\begin{array}{l}\text { Sea level during storm } \\
\text { surge + SLR }\end{array}$ & 50 & 0.128 & 3.00 & 0.0746 & 0.290 & 0.777 & 14.052 & 0.0091 & 0.0120 \\
\hline \multirow[t]{2}{*}{ Standing } & $\begin{array}{l}\text { Sea level during storm } \\
\text { surge + SLR }\end{array}$ & 10 & 0.121 & 2.23 & 0.0746 & 0.290 & 2.107 & 7.764 & 0.0155 & 0.0230 \\
\hline & $\begin{array}{c}\text { Sea level during storm } \\
\text { surge }+ \text { SLR }\end{array}$ & 50 & 0.128 & 3.00 & 0.0746 & 0.290 & 1.992 & 14.052 & 0.0091 & 0.0120 \\
\hline
\end{tabular}
overtopping conditions are less than 0.65 . Thus, Equations (6) and (7) can be used to compare the overtopping discharge in this study.

Table 4. Parameters to compare overtopping discharge at the model scale.

Figure 9 shows the relative overtopping discharge with respect to the relative free board. Based on the relative free board, the standing barrier is compared with Equation (6), and the non-standing barrier is compared with Equation (7). For the non-standing barrier, overtopping discharges are less than the results of the EurOtop, except for the minimum relative free board (which is the case for the 50-year return period and the sea level during the storm surge with the SLR in Table 4) because the wave energy is reduced by armor units, and the vertical wall has a short overhang that minimally blocks wave overtopping. However, the overtopping discharge is about 1.2 times greater than the predicted results 
at the minimum relative free board, presumably because the wave energy is not reduced by the armor units because of high incident wave conditions. For the standing barrier, the overtopping discharges are less than those of EurOtop, since incident waves are returned to the seaside by two bullnoses. To secure the right view, the height of the standing movable barrier should be decreased. Thus, the height of the bullnose should be increased and the number of the bullnose should be increased to reduce wave overtopping.

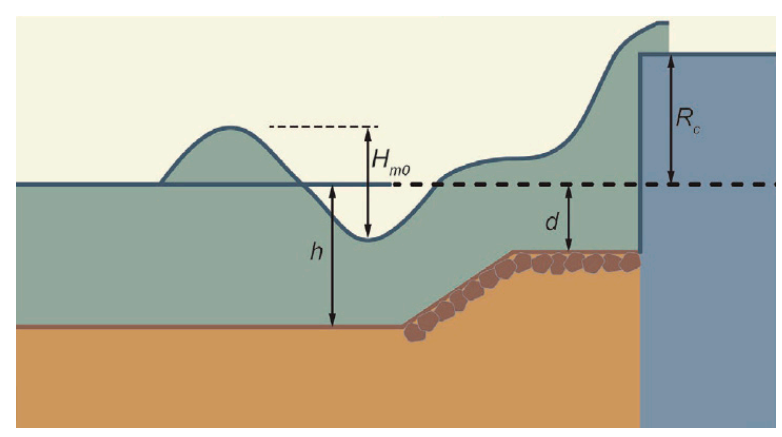

(a)

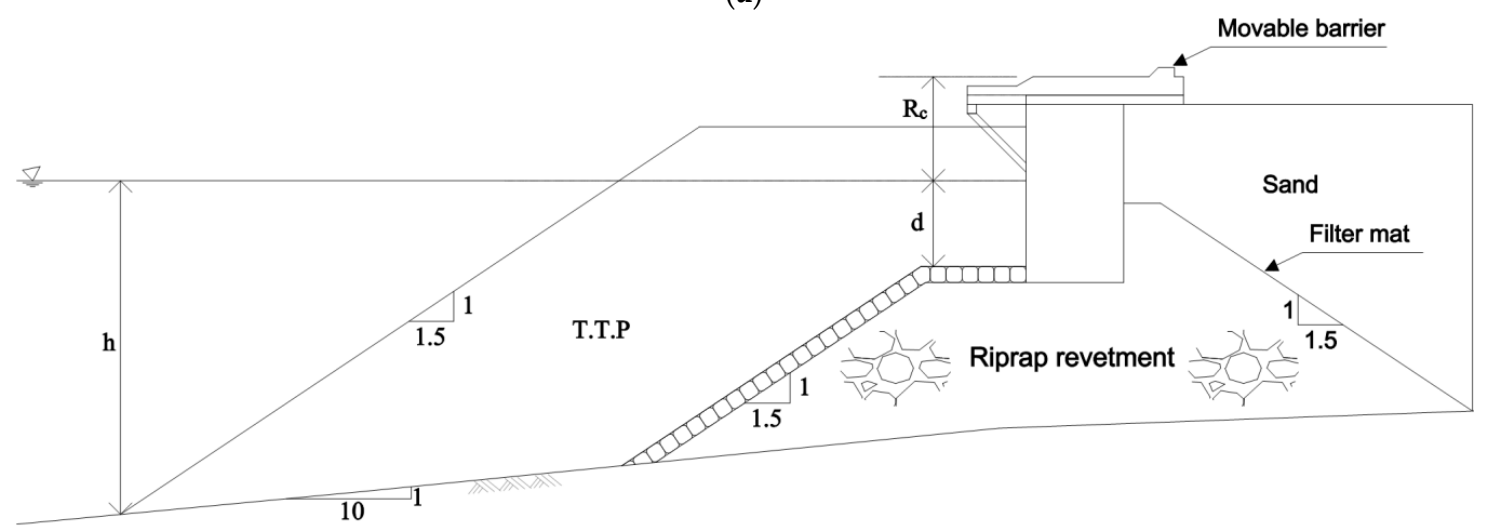

(b)

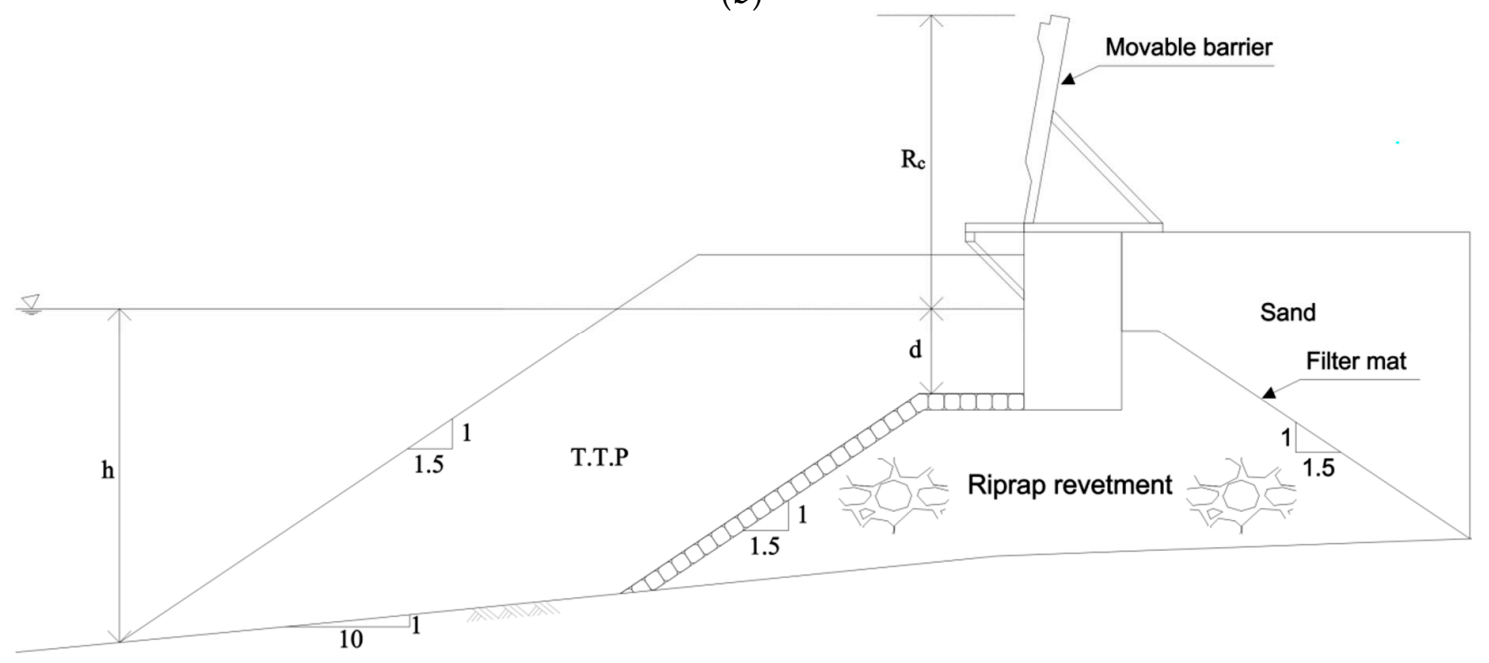

(c)

Figure 8. Definition of the related parameters; (a) composite vertical wall in the EurOtop manual; (b) non-standing barrier; (c) standing barrier. 


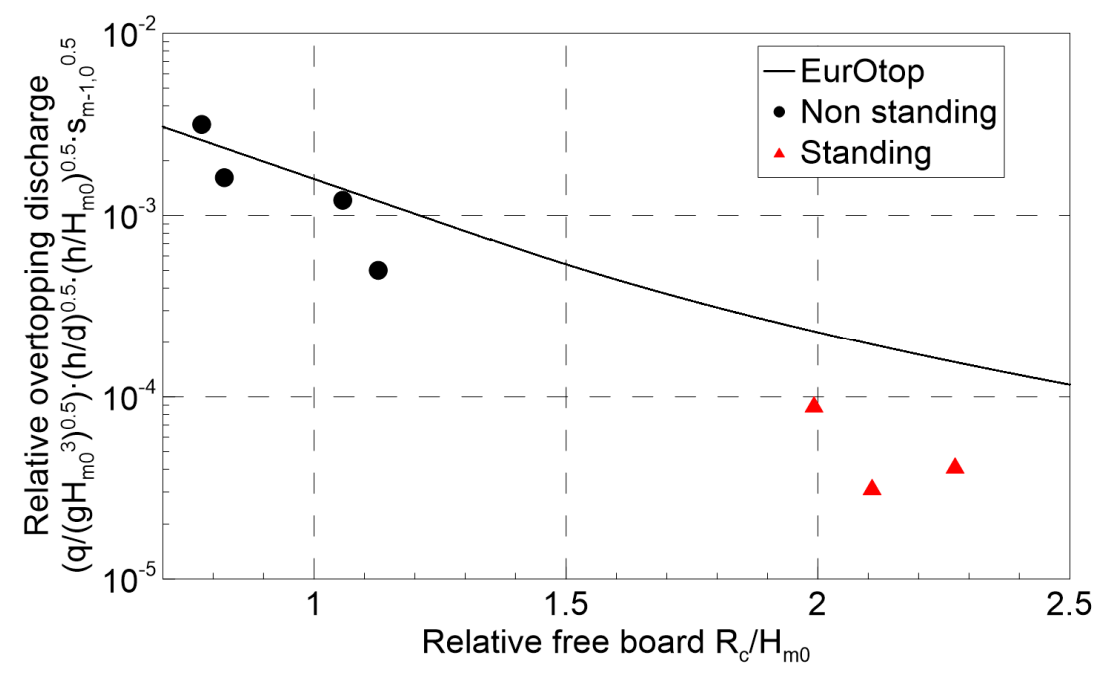

Figure 9. Comparison of the relative overtopping discharge between the measured data and the prediction equation suggested by EurOtop.

\subsection{Uplift Pressure and Wave Pressure}

In this section, the uplift pressure and the wave pressure acting on the movable barrier are analyzed to confirm the occurrence of impulsive pressures. Barriers should be in the "standing state" for all cases, considering the results of the wave overtopping in Table 3. However, the uplift pressure is measured on the assumption that the designed sea level is the approx. H.H.W. and that the barrier will not stand during the 10-year return period in this section. A non-standing barrier is important to analyze the uplift pressure acting on the bottom of the barrier. An impact on the bottom of the barrier occurs when a large incident wave propagates to the barrier. For this reason, the movable barrier can be broken, making the hinterland more dangerous.

Figure 10 shows the result of the uplift pressure at $\mathrm{p}_{4}$ in Figure $5 \mathrm{a}$ for the 10-year return period and the approx. H.H.W. (No. 1, Table 2). The y-axis is the uplift pressure nondimensionalized by the hydrostatic wave pressure for the maximum wave height, $\mathrm{H}_{\max }$. The maximum wave height is $19.5 \mathrm{~cm}$. The total generation time is $30 \mathrm{~min}$. This figure shows results in the range around the maximum pressure. Relative uplift pressures greater than 1 occur about 20 times during the total generation time. The maximum relative uplift pressure is 2.12, as shown in Figure 10. This means that the impulsive pressure acts on the bottom of the movable barrier. The impulsive pressure is inversely proportional to its duration. The impulsive pressure becomes especially higher when the incident wave height increases, and the distance between the water surface and the horizontal structure (i.e., non-standing barrier) decreases. If the weight of the movable barrier is increased to secure the barrier's stability, additional ground reinforcements on the target site may be needed. However, adding such reinforcements is difficult and costly work. To ensure stability, three options are possible: (1) The movable barrier could be installed closer to the landside to avoid impulsive pressure from acting on the bottom of the non-standing barrier; (2) the distance between the water surface and the non-standing barrier could be increased; (3) the number of armor units could be increased at the seaside to reduce the wave's energy.

The movable barrier stands by the rise of the sea level and the wave overtopping during storms, which is needed to determine the wave pressure acting on the movable barrier facing the outer sea in an abnormal state. Figure 11 shows the results of the wave pressure at $\mathrm{p}_{4}$ and $\mathrm{p}_{5}$ in Figure $5 \mathrm{~b}$ for the 50-year return period and the sea level during the storm surge with the SLR (No. 4, Table 2), because the maximum wave pressure acting on the movable barrier is important in terms of a design perspective. The maximum wave height of the y-axis is $23.4 \mathrm{~cm}$. Relative wave pressures greater than 2 occur four times during the total generation time. The maximum relative wave pressures at $\mathrm{p}_{4}$ and $\mathrm{p}_{5}$ are 3.84 and 3.50 , respectively. Furthermore, it can be seen that the maximum impulsive pressures 
continuously occur from $\mathrm{p}_{4}$ to $\mathrm{p}_{5}$, with a time difference of $0.01 \mathrm{~s}$. As the result of this experiment, the movable barrier should be designed while considering impulsive wave pressure. To avoid the impulsive pressure for the standing movable barrier, a slit structure needs to be installed under the movable barrier, and the number of armor units should be increased to the seaside to reduce the wave energy.

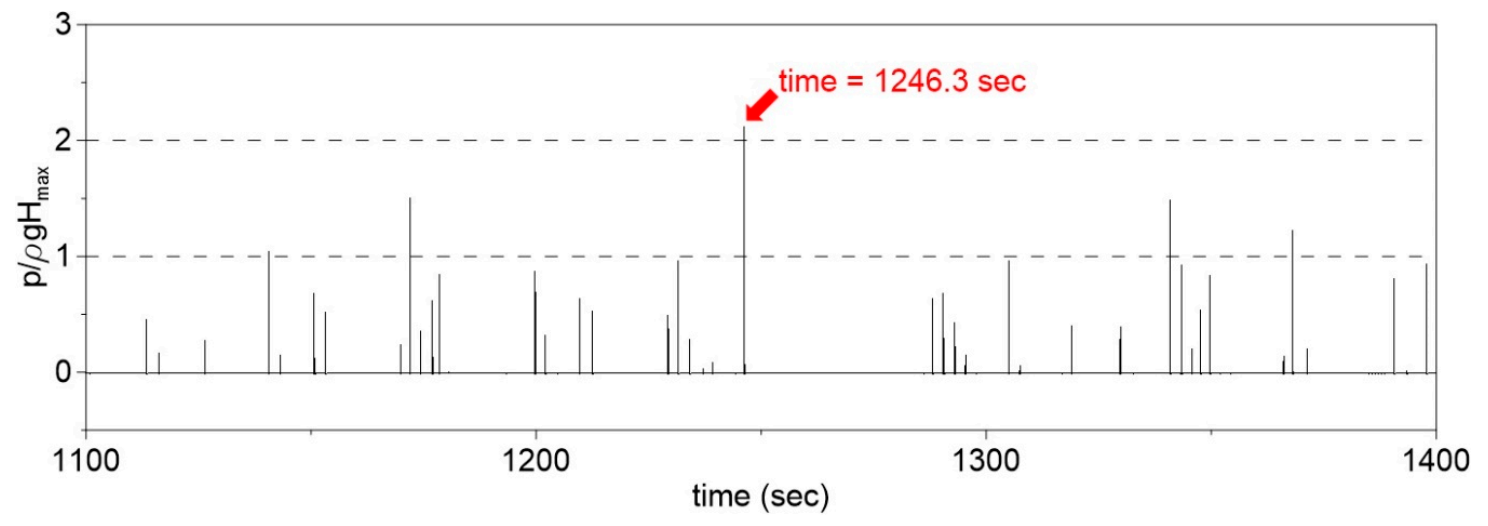

Figure 10. Time series of the measured uplift pressures at $\mathrm{p}_{4}$ in Figure 5a.

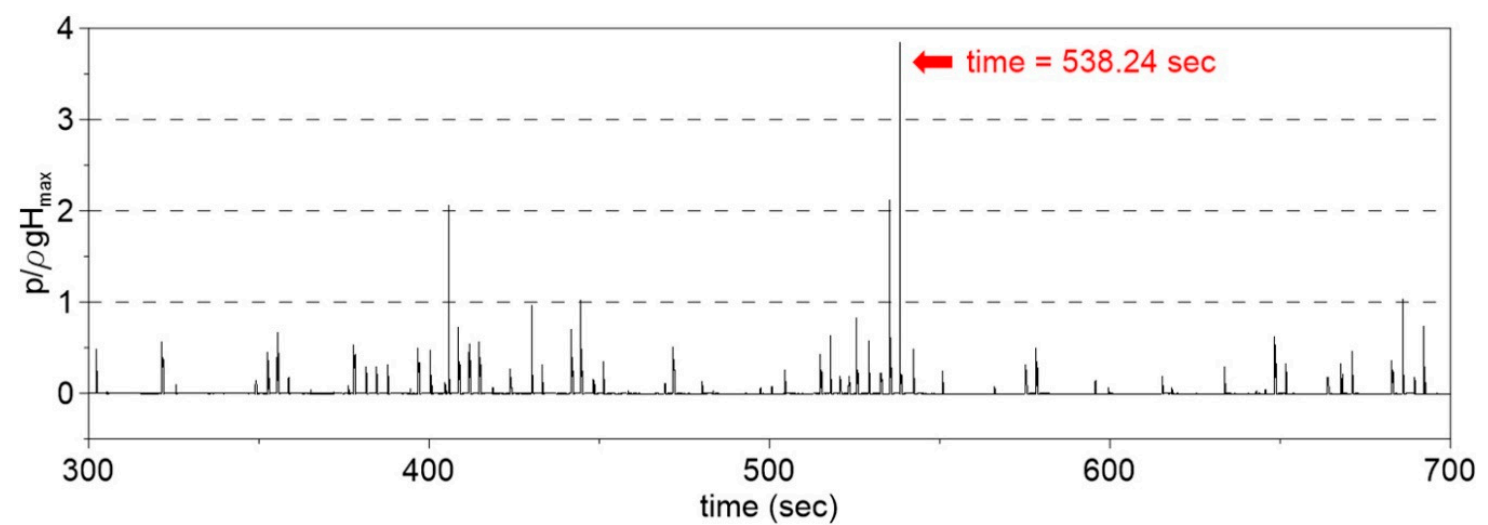

(a)

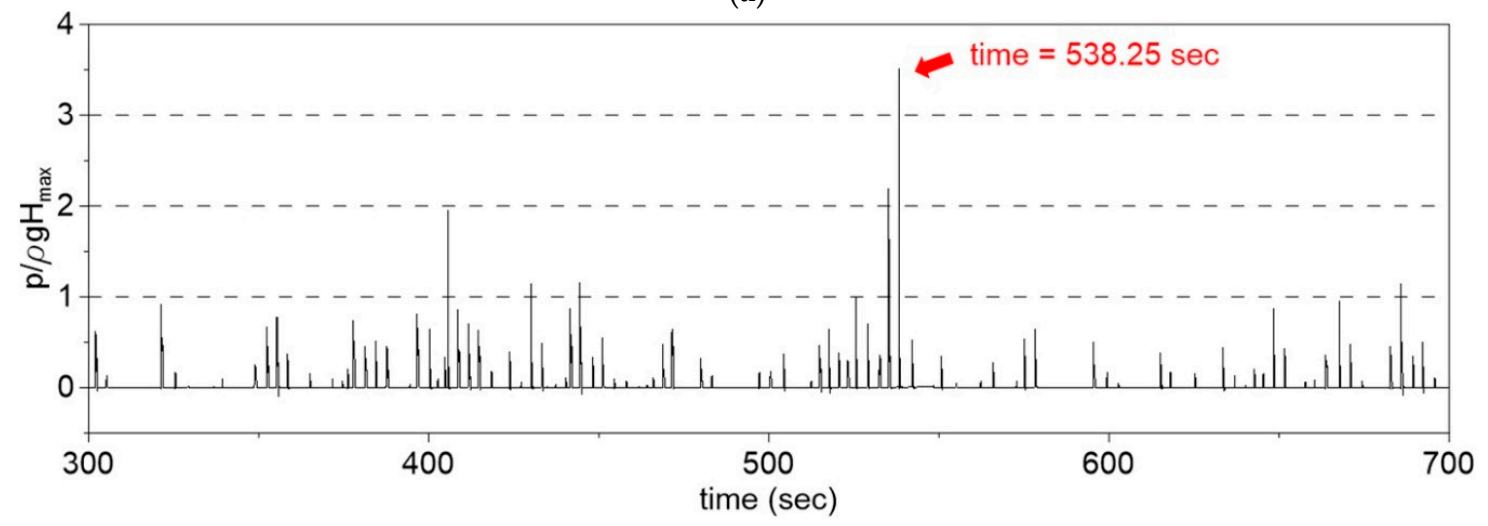

(b)

Figure 11. Time series of the measured wave pressures; (a) at $\mathrm{p}_{4}$ in Figure $5 b ;(\mathbf{b})$ at $\mathrm{p}_{5}$ in Figure 5 b.

An impulsive wave can be of a Wagner type or a Bagnold type [25-27]. The impulsive pressure of the Wagner type shows a momentary peak and is caused by the direct impact of the water mass. The impulsive pressure of the Bagnold type has two characteristics: (1) A vibration occurs after the peak; (2) air pockets are created by being entrapped by the breaking wave. For the similitude ratio, the Froude similarity can be applied to the Wagner type and the compression law can be applied to the 
Bagnold type. In this experiment, the results of the impulsive wave are almost a Wagner type. Thus, to apply these results in the design of the target site, it would be useful to apply the Froude similarity.

\section{Conclusions}

In this study, a movable barrier was preliminarily designed for the target site, and the discharge of the wave overtopping and the wave pressure acting on the movable barrier was measured through physical experiments in the wave flume. The results obtained through the physical experiment are summarized as follows.

The discharge of the wave overtopping is less than $0.01 \mathrm{~m}^{3} /(\mathrm{m} \mathrm{s})$ of the allowable limit for all cases when the movable barrier stands up.

For the standing movable barrier, all cases of overtopping discharge are less than the composite vertical wall suggested by the EurOtop, since two bullnoses on the movable barrier are reflected in the incident wave well.

Impulsive wave pressure acting on the movable barrier was frequently detected. Notably, the maximum relative wave pressure $\left(\mathrm{p}_{4}\right.$ and $\left.\mathrm{p}_{5}\right)$ is greater than 3 in Figure 11 when the movable barrier stands up.

The movable barrier is well designed to block wave overtopping. However, to avoid impulsive pressure, engineers should design a slit structure under the movable barrier to reduce the wave energy.

In the future, a physical experiment will be carried out for the newly designed movable barrier, reflecting the results of this study on this target site, and numerical simulations will also be carried out to determine the mechanism of the movable barrier for various cases.

Author Contributions: Experiment, B.W.L.; methodology, D.W. and W.-S.P.; data curation, B.W.L. and J.S.; writing—original draft preparation, B.W.L.; writing—review and editing, D.W. All authors have read and agreed to the published version of the manuscript.

Funding: This research was supported by the Korea Institute of Marine Science and Technology Promotion grant funded by the Ministry of Ocean and Fisheries (No.20170039).

Conflicts of Interest: The authors declare no conflict of interest.

\section{References}

1. Yamada, Y.; Satoh, M.; Sugi, M.; Kodama, C.; Noda, A.T.; Nakano, M.; Nasuno, T. Response of tropical cyclone activity and structure to global warming in a high-resolution global nonhydrostatic model. J. Clim. 2017, 30, 9703-9724. [CrossRef]

2. The Intergovernmental Panel on Climate Change. Global Warming of $1.5^{\circ} \mathrm{C}$; The Intergovernmental Panel on Climate Change: Geneva, Switzerland, 2019.

3. Van der Meer, J.W.; Allsop, N.W.H.; Bruce, T.; De Rouck, J.; Kortenhaus, A.; Pullen, T.; Schüttrumpf, H.; Troch, P.; Zanuttigh, B. Manual on wave overtopping of sea defences and related structures. An overtopping manual largely based on European research, but for worldwide application. EurOtop. 2018. Available online: www.overtopping-manual.com (accessed on 20 December 2019).

4. Gensen, M. Wave Overtopping in Harbour Areas. Master's Thesis, Delft University of Technology, Delft, The Netherlands, March 2017.

5. Lehmann, H.A.; Jasper, H. Tidal barriers at the North and Baltic Sea Coast. Die Küste 74 ICCE 2008, 74, 212-232.

6. Kendrick, M. The Thames Barrier. Coast. Eng. 1988, 16, 57-68. [CrossRef]

7. Bol, R. Flooding and Environmental Challenges for Venice and Its Lagoon: State of Knowledge, 1st ed.; Cambridge University Press: Cambridge, UK, 2005; pp. 311-316.

8. Hunter, P. The St Petersburg Flood Protection Barrier: Design and Construction; CETMEF PIANC: Paris, France, 2012.

9. Venice Flood Barrier: MOSE Project Keeps the Sea at Bay. Available online: http://eandt.theiet.org/magazine/ 2014/08/venice-master-of-water.cfm (accessed on 8 December 2019). 
10. Seo, J.; Lee, B.W.; Park, W.S.; Won, D. Behavior of a moveable barrier on revetment for mitigation of disaster by wave overtopping. J. Korean Soc. Coast. Ocean Eng. 2018, 30, 10-18. (In Korean) [CrossRef]

11. Cuomo, G.; Allsop, W.; Bruce, T.; Pearson, J. Breaking wave loads at vertical seawalls and breakwaters. Coast. Eng. 2010, 57, 424-439. [CrossRef]

12. Oh, S.H.; Lee, J.S.; Lee, J. Introduction to Physical Experiment Building of KIOST in Busan. In Proceedings of the 10th International Conference on Asian and Pacific Coasts 2019 (APAC 2019), Hanoi, Vietnam, 25-28 September 2019; Trung Viet, N., Xiping, D., Thanh Tung, T., Eds.; Springer: Singapore, 2020; pp. 221-226.

13. Lykke Andersen, T.; Clavero, M.; Firgaard, P.; Losada, M.; Puyol, J.I. A new active absorption system and its performance to linear and non-linear waves. Coast. Eng. 2016, 114, 47-60. [CrossRef]

14. Meinert, P.; Lykke Andersen, T.; Frigaard, P. AwaSys 7 User Manual; Aalborg University: Aalborg, Denmark, 2017.

15. Oh, S.H.; Lee, J.; Lee, J.S. Experimental investigation of the wave force on the caisson according to different coverage of armor units. In Proceedings of the 10th International Conference on Asian and Pacific Coasts 2019 (APAC 2019), Hanoi, Vietnam, 25-28 September 2019; Trung Viet, N., Xiping, D., Thanh Tung, T., Eds.; Springer: Singapore, 2020; pp. 987-993.

16. Hasselmann, K.; Barnett, T.P.; Bouws, E.; Carlson, H.; Cartwright, D.E.; Enke, K.; Ewing, J.A.; Gienapp, H.; Hasselmann, D.E.; Kruseman, P.; et al. Measurements of Wind-wave Growth and Swell Decay During the Joint North Sea Wave Project (JONSWAP); Deutches Hydrographisches Institut: Hamburg, Germany, 1973.

17. Lykke Andersen, T.; Eldrup, M.R.; Firgaard, P. Estimation of incident and reflected components in highly nonlinear regular waves. Coast. Eng. 2017, 119, 51-64. [CrossRef]

18. Haeundae-gu Office. Feasibility Study and Master Plan Report for Storm Surge Risk Zone on Suyeong Bay; Haeundae-gu Office: Busan, Korea, 2016. (In Korean)

19. Korea Hydrographic and Oceanographic Administration. Analysis and Prediction for Sea Level Fluctuation, 5th ed.; Korea Hydrographic and Oceanographic Administration: Busan, Korea, 2013. (In Korean)

20. Korea Real Time Database for NEAR-GOOS by Korea Hydrographic and Oceanographic Administration. Available online: http://www.khoa.go.kr/koofs/eng/observation/obs_real.do (accessed on 8 December 2019).

21. Ministry of Maritime Affairs and Fisheries. Basic and Detailed Design for Development Project of Marina Port on Haeundae-Gu; Ministry of Maritime Affairs and Fisheries: Busan, Korea, 2019. (In Korean)

22. Ministry of Maritime Affairs and Fisheries. Harbor and Fishery Design Criteria; Ministry of Maritime Affairs and Fisheries: Busan, Korea, 2017. (In Korean)

23. Oh, S.H. Analysis of the effect of reducing wave overtopping by wave return walls. J. Korean Soc. Coast. Ocean Eng. 2016, 28, 1-6. (In Korean) [CrossRef]

24. Kerpen, N.B.; Schoonees, T.; Schlurmann, T. Wave overtopping of stepped revetments. Water 2019, 11, 1035. [CrossRef]

25. Kim, S.S.; An, D.H.; Chun, I.S. Wave impact pressures acting on the underwater tunnel bulkhead under construction-Numerical analysis and hydraulic model experiment. J. Korean Soc. Coast. Ocean Eng. 2011, 23, 139-146. (In Korean) [CrossRef]

26. Park, W.S.; Ahn, H.D. An efficient model for dynamic analysis of caisson breakwaters under impulsive wave loadings. J. Korean Soc. Coast. Ocean Eng. 1995, 7, 108-115. (In Korean)

27. Takahashi, S.; Tanimoto, K.; Suzumura, S. Generation mechanism of impulsive pressure by breaking wave on a vertical wall. Rep. Port Harb. Res. Inst. 1983, 22, 3-31. (In Japanese)

(C) 2019 by the authors. Licensee MDPI, Basel, Switzerland. This article is an open access article distributed under the terms and conditions of the Creative Commons Attribution (CC BY) license (http://creativecommons.org/licenses/by/4.0/). 